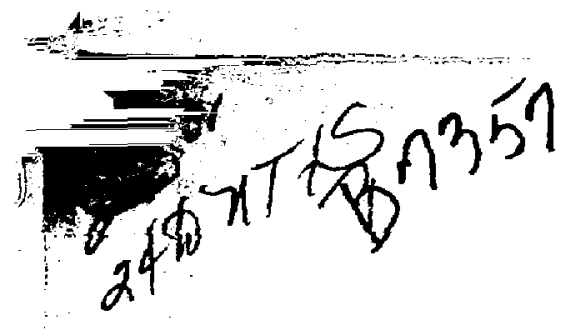

\title{
MASTER
}

TANDEN-HIRROR

\section{TECHNOLOGY DEMONSTRATION FACILITY}

$T$. Kenneth Fowler

B. Grant Logan

September 18, 1981

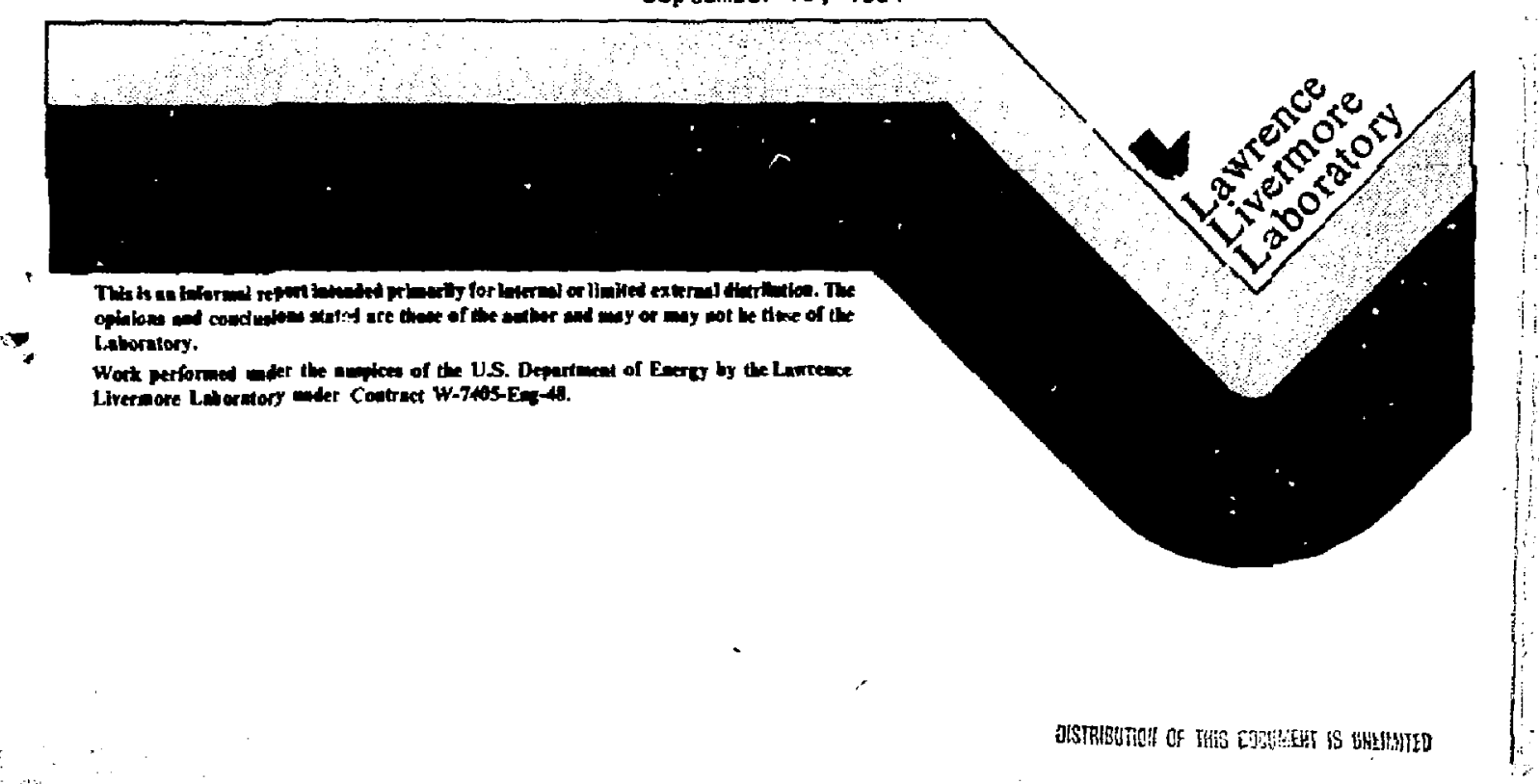


TANDEM-MIRROR TECHNOLOGY DEMONSTRATION FACILITY

T. K. Fowler and B. Grant Logan*

Lawrence Livermore National Laboratory

Preliminary calculations at LLNL indicate that a Technolony Demonstration facility (TOF) consisting of a tandem mirror machine ahout the size of TMX could begin providing fusion nuclear enqineering dat a as early as 1988. With hioh density operation based on physics already demo strated in TMX, this machine would produce 12 MW of DT neutrons in steady-st te from a plasma column $0.08 \mathrm{~m}$ in radius and $8 \mathrm{~m}$ in length (see Fig. 1). A lowing space for neutral beam injectors at each end of the column, this would permit testing of blanket modules and components at $1 \mathrm{MW} / \mathrm{m}^{2}$ neutron wall load over a cylindrical surface $8 \mathrm{~m}^{2}$ in area at a radius of $0.25 \mathrm{~m}$; or one could irradiate thousands of small samples at $2 \mathrm{MW} / \mathrm{m}^{2}$ at $r=0.125 \mathrm{~m} 14 \mathrm{~m}^{2}$ area). With improved end-plug physics to be tested in TMX-Upgrade in 1982-83, the wall load at $0.25 \mathrm{~m}$ could be increased to $2 \mathrm{MW} / \mathrm{m}^{2}\left(4 \mathrm{MW} / \mathrm{m}^{2}\right.$ at $\left.r=0.125 \mathrm{~m}\right)$. Construction of the TOF could begin in FY84 and be completed in 4 to 5 years, at a cost roughly est imated as $\$ 700 \mathrm{M}$ in 181 dollars including engineering and 30\% contingency.

To produce copious neutrons in a small device, we utilize the fact that even smalt mirror machines have confined dense plasmas at high ion temperatures and, because of the small volume, neutral beams can maintain these plasmas in steady state with modest demands on the plasma conf inement time. This was the principle behind the earlier Fusion Engineering Research Facility (FERF) based on a yin-yang mirror geometry. 1 The tandem mirror version has the advantages of a somewhat lower machine cost, simpler construction and a configuration in the mainstream of tandem mirror reartor development. Follow-on tanden mirror devices (TMNS, Demo) wauld be scaleups of the TDF geometry with correspondingly improved confinement properties

\footnotetext{
* We wish to acknowledge the help of many people in carrying out this preliminary assessment of the tandem mirror TDF: C. Damm (operating scenarios); $M$. Rensink (Fokker-Planck calculations); D. E. Baldwin, L. D. Pearlste in (stability assessment); A. Chargin, J. Doggett, R. Bulmer, R. Wong (magnet design); C. D. Henning (copper magnets, cost estimate); V. Karpenko, $T$. Kozman (cost est imate).
} 
needed to reach ignition in the center cell. The TDF itself would be a driven device $(Q=0.3$ for the base case $)$.

For the TOF base case, 68 MW of $80 \mathrm{keV}$ neutral beam power (half $D$, half $T$ ) is injected into the center cell to sustain a mirror-confined ion density of $7 \times 10^{14} \mathrm{~cm}^{-3}$ at an average energy of $39 \mathrm{keV}$. In this mode of tandem mirror operation, known as the kelley mode, the erid cells serve three functions. They provide MHD stability; they eliminate axial ambipolar electric fields in the center cell that would otherwise degrade mirror confinement there; and they serve to confine low energy ions that fill in the loss cone in the center cell. Loss cone instability in the end cells themselves is "stream stabilized" by the outflow of low energy ions from the center ce11, regulated by the input of gas to the center cell. This method of stabilization, successfully demonstrated in TMX, carries the penalty of reduced electron temperature and hence enhanced center-cell losses by ion-electron drag. Higher electron temperat'ures and performance better than the base case would result if the ToF end cells can be operated stably with thermal barriers, to be tested in TMX-Upgrade in 1982-83. Whether oi not thermal barrier physics is incorporated in the TDF final design would have little impact on project cost and schedule. Thermal barriers are not required for the base case performance providing testing capability at neutron fluxes of 1 to $2 \mathrm{MW} / \mathrm{m}^{2}$ as noted above.

With neutral beam injection in the center cell, TMX perfurmed in a manner similar to the TDF base case. The TMX and TDF parameters are compared in Tables 1 and 2. The most interesting results from these experiments were the large peak value of beta achieved ( $40 \%$ for the center cell mirror-confined component) and, under most circumstances, the absence of noise at the center-cell ian cyclotron frequency (no center-cell loss cone instability). In TMX, because the beams were injected perpendicular to the axis, the high-beta region was localized around the footprint of the beams (about $1 \mathrm{~m}$ ). As can be seen from the tables, the main difference between TDF and TMX is the much higher center-cell magnet ic field and plasma density in the Tof. Note that the $2 \times I I B$, which was a stream-stabilized single mirror experiment, achieved a hot ion density of $10^{14} \mathrm{~cm}^{-3}$ intermediate between TMX and TDF.

Despite the large extrapolation in field and density, there is a scund basis in theory and experiment to expect that the TDF plasma will be stable and that the machine will perform according to calculations. Regarding loss cone instability, Fokker-Planck calculations have shown that, with an input of 
gas consistent with the requirements of stream stabilization of the end cells, electron drag on the mirror-confined hot ions in the center cell and collisional heating of the cold ions confined by a $1 \mathrm{kV}$ potential barrier leads to a total ion distribution $\int d{ }_{11} f$ that is a monotonic-decreasing function of $v_{1}^{2}$ and hence stable to electrostatic ion-cyclotron (loss cone) instabilities (DCLC, convective mode, etc.). Moreover, by injecting the beams skew to the axis as shown in Fig. 1 , the pressure is sufficiently isotropic that the Alfven Ion Cyclotron (AIC) mode should be stable at the desired beta values. Though somewhat inferential, the theoretical explanation of a host of mirror experiments from $P R 6$ and $2 \times I I B$ to TMX has been taken as good conffrmation of the "monotonic-function" stability criterion, which also has a strong foundation in plasma theory. The AIC mode has not yet been identified in experiments even at the very high beta values obtained in $2 X I I B$, though this may have been a consequence of the short length of the plasma in that experiment.

Theoretical estimates indicate that radial losses, relatively weak in TMX, should also be unimportant in TOF. Our main concern is resonant transport, which increases with ian energy but is more than comnensated by the axisymetric design of the TDF center cell as compared with the non-symmetric TMX. Regarding classical radial transport, note that the energetic ion lifetime in TDF is only one collision time, and the low energy ions suffer fewer collisions than those in TMX. Concernirg instabilities that might calise radial losses, a first-cut analys is shows that rotationa? modes are stable because the radiaislectric field is relatively weak. Other modes, though posisily of concern at the onger plasma lifetimes to be encountei ed in MFTF-B and TMNS, probably are not of concern in TDF, where the lifetime is similar to that in TMX and earlier mirror experiments (10 msec for the hot component). Turning to MHO stability and beta, the TDF magnet desian is similar to the TARA design with end cells consisting of two mirror machines in series, the first being a high-field axisymetric mirror with circular coils in which the potential barrier is produced (the "end plug"), followed by a minimum-B "anchor" that provides MHD stability (see Fig. 2). While this differs from the TMX design, experience with TMX, Phaedrus and other mirror devices (as well as the computational tools developed in designing iMX-U, MFTF-B, etC.) gives us confidence that tandem mirror magnet systems can be designed by calculation, with respect to orbit confinement, plasma equilibrium and MHO stability prope cies. According to our calculations thus far, the TOF should 
$-4-$

be stable to interchange modes well within the design beta values, and we expect the small plasma radius to prevent "ballooning" instability by finite Larmor radius stabilization. Moreover, as noted above, the design beta value has already been achieved in TMX with beam injection in the center cell (Tocally 40\%).

Regarding the schedule, the estimate of 4 to 5 years construction time is based on the similarity in scope between MFTF-B and the TDF machine (more beam power in TDF, less superconducter). Another factor influencing our schedule estimate is the anticipated R\&D required. The main development task is to upgrade the $80 \mathrm{kV}$ MFTF beams for reliable steady-state operation in the neutron environment of TDF. We believe this will turn out to be manageable at the fluxes incident at the neutral beam source locations; though large at small radii, the flux decreases with the square of the distance. The greatest schedule (and cost) uncertainty concerns site selection, the building and the special problems of nuclear operation such as remote mainterance and tritium handling, which account for $35 \%$ of our rough cost estimate. Another special requirement is the disposal of low-level nuclear waste in the course of maintenance and ultimate decomissioning of the facility. While the latter point needs considerably more study, it is our belief that it will be possible to choose practical materials that can be disposed of safely on site and that this should be made a goal of TBF.

The most novel components in the TDF, though probably not requiring major development, are the high-field, circular coils at each end of the solenoid. The TOF end plug design is based on ideas that have evolved out of our tandem mirror reactor studies during the past year and which we now believe will be the optimum design for TMNS and follow-on tandem mirror reactors. The new features are a higher field in the center cell and much smatler end plug magnets with low capital cost. The higher center-cell field greatly reduces the cross-sectional area of the plasma column for a given power output (area $\propto \mathrm{B}^{-4}$ ). Consequently the end plugs can be smaller; and the plug size $c$ an be further reduced if the mirror fielci strength is large. This led to the idea of sma11, high-field end plugs using unshielded, water-cooled, circular copper coils ("throw away" plugs) inserted in a superconducting solenoid. Because they are small, the power to run these coils would not degrade $Q$ very much. For the TUF, the circular plug magnets would be $0.26 \mathrm{~m}$ outer radius with a field of $15 \mathrm{~T}$ at the conductor $(8 \mathrm{~T}$ from the copper, $7 \mathrm{~T}$ from the solenoid), and would consume about $35 \mathrm{MN}$ (both olugs). 
Like TDF, future machines would also have a minimum-8 magnet at each end to serve as a plasma "anchor" to insure MHD stability. Ultimately these anchors might prove unnecesssary (e.g. if hot electrons stabilize the circular plugs, as in EBT). In any case, with small plugs, the anchors would also be small; in TDF, they are copper baseball coils the size of the TMX end piugs. The TDF solenoid design would be based on data from the MFTF-B construction project (as TOF would in turn provide design data for TMNS). Based on work at MIT and elsewhere, the high-field copper plug magnets prabably would not require major development for TDF, but would require development for TMNS and later applications.

The TDF schedule fits well in a tandem mirror development sequence (see Table 3). As we have stated, the physics base for TOF comes mainly from TMX, with further evidence that the tandem mirror is on the right track expected in the period 1982-84 prior to major hardware commitments (from TMX-U, as well as TMX-S, TARA, Gamma 10--Japan, and Ambal--USSR). The physics base for TMNS comes mainly from MFTF $B$. If TDF construction begins in FYB4, the device could be completed by 1988. While the TDF produces nuclear engineering data, based on MFTF-B results in 1985-86 one could begin in 1987 to construct TMNS which would constitute a complete nuclear core for a tandem mirror experimental reactor, including appropriate end-plugs and a shielded solenoid $25 \mathrm{~m}$ in length (about the same as MFTF-B). In parallel with tests in TMNS, beginning in 1993 one could begin blanket modicications and balance-of-plant that would upgrade TMNS to a 200 MHe demo by 1997. At that $t$ ime TOF would have provided 8 years of nuclear data which, together with TMNS-Demo, would provide the data base for a commercial demonstration plant before the year 2000.

\section{REFERENCE}

1. T. H. Batzer et al., "Coñceptual Design of a Mirror Reactor for a Fusion Engineering Research Faciijty (FERF)," UCRL-51617, Aug. 1974. The present tandem mirror TO'r ras stimulated by an update of the FERF study by J. N. Doggett and C. C.. Darm, "Conceptual Design of a Technology Demonstration Facility (TDF)," UCRL-85999, Sept. 1981. 
$-6-$

TABLE 1. TANDEM MIRROR PARAMETERS--CENTER CELL

\begin{tabular}{|c|c|c|c|}
\hline & $\begin{array}{l}\text { TMX } \\
\text { with center } \\
\text { cell injection }\end{array}$ & $\begin{array}{c}\text { rof } \\
\text { base case } \\
\text { (stream-stabilized) } \\
\text { plugs }\end{array}$ & $\begin{array}{c}\text { TOF } \\
\text { upgrade } \\
\text { (thermal-barrier) } \\
\text { plugs }\end{array}$ \\
\hline $\begin{array}{l}\text { Plasma length (m) } \\
\text { plasma radius }(\mathrm{m}) \\
\text { Solenoid fieid }(\mathrm{T}) \\
\text { Peak beta } \\
\text { Electron } \\
\text { temperature (kev) }\end{array}$ & $\begin{array}{l}5 \\
0.22 \\
0.20 \\
0.40 \\
0.20\end{array}$ & $\begin{array}{l}8 \\
0.08 \\
4.5 \\
0.40 \\
2.3\end{array}$ & $\begin{array}{l}8 \\
0.12 \\
4.5 \\
0.53 \\
5.0\end{array}$ \\
\hline $\begin{array}{l}\text { Hot-ion average } \\
\text { energy (kev) }\end{array}$ & 10 & 39 & 56 \\
\hline $\begin{array}{l}\text { Larmor arbits } \\
r_{c} / \rho_{i} \text { (hot) }\end{array}$ & 2 & 8 & 10 \\
\hline $\begin{array}{l}\text { Hot-ion lifetime } \\
\text { (msec) }\end{array}$ & $0.75 *$ & 10 & 14 \\
\hline $\begin{array}{l}\text { Hot-ion density } \\
(\mathrm{cm}-3)\end{array}$ & $4 \times 10^{12}$ & $6.9 \times 10^{14}$ & $6.1 \times 10^{14}$ \\
\hline $\begin{array}{l}\text { Warm-ion temperature } \\
\text { (keV) }\end{array}$ & 0.1 & 6 & 10 \\
\hline $\begin{array}{l}\text { Warm-ion lifet ime } \\
\text { (msec) }\end{array}$ & 2.5 & 0.5 & 5.0 \\
\hline $\begin{array}{l}\text { Warm-jon density } \\
\left(\mathrm{cm}^{-3}\right)\end{array}$ & $1.5 \times 10^{13}$ & $6.3 \times 10^{13}$ & $9.2 \times 10^{13}$ \\
\hline $\begin{array}{l}\text { Potential well (kv) } \\
\text { Beam voltage }(k v)\end{array}$ & ${ }_{17}^{0.15}$ & $80^{1.1}$ & $80^{6.6}$ \\
\hline $\begin{array}{l}\text { Incident beam power } \\
\text { (MW) }\end{array}$ & 0.84 & 68 & 68 \\
\hline $\begin{array}{l}\text { Trapped beam atom } \\
\text { current (A) }\end{array}$ & 36 & $870(50 \% 0,50 \% T)$ & 1070 \\
\hline Trapped gas feed (A) & 300 & 1750 & 230 \\
\hline Fusion power (MW) & -- & 15 & 27 \\
\hline $\begin{array}{l}Q \text { (center cell) } \\
\text { Neutron wall flux } \\
\left(M \omega / \mathrm{m}^{2}\right)\end{array}$ & -- & 0.3 & 0.43 \\
\hline $\begin{array}{l}\text { at } r=0.25 \mathrm{~m} \\
\text { at } r=0.125 \mathrm{~m}\end{array}$ & $=$ & $\begin{array}{l}1.0 \\
2.0\end{array}$ & $\begin{array}{l}2.0 \\
4.0\end{array}$ \\
\hline
\end{tabular}

* Lifetime limited by charge exchange. At higher fields and smaller orbits better shielded from neutrals, $10 \mathrm{keV}$ ions in 2 XIIB had lifetimes up to 4 msec. 
$-7-$

TABLE 2. TANDEM MIRROR PARAMETERS--END CE:.LS

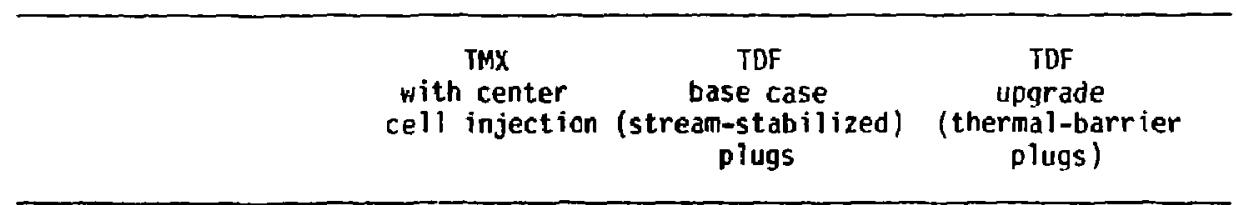

End Plugs

i 'asma length (m)

Plasma radius (m)

Plasma density $\left(\mathrm{cm}^{-3}\right)$

Field at mirror (T)

Field at midplane $(T)$

Peak beta (end plug)

Particle energy ( $k \mathrm{ev}$ )

Larmor orbits

$r_{p} / \rho_{i}$

Electron confining

potential

$\phi_{\mathrm{e}}(k V)$

Injection power (MW)

(per plug)

$\begin{array}{ll}1.1 & 1.0 \\ 0.1 & 0.064 \\ 3 \times 10^{13} & 1.2 \times 10^{15} \\ 2 & 15 \\ 1 & 7.5 \\ 0.12 & 0.5 \\ 10 \text { (ion) } & 60 \text { (ion) } \\ 5 & 8.4\end{array}$
2.75
0.18
$2.1 \times 10^{13}$
15
2
0.5
240 (electron)
NA

$\begin{array}{lll}0.6 & 11.7 & 29\end{array}$

$\begin{array}{lll}0.30 & 3.3 & 0.41\end{array}$

(17 kV beams) ( $80 \mathrm{kV}$ beams) (60 GHz ECRH)

$3.0 \mathrm{MW}$

(40 kV pump beams)

Anchors

$\begin{array}{llll}\text { Plasma length (m) } & -- & 1.2 & 1.2 \\ \text { Plasma radius (m) } & -- & 0.14 & 0.20 \\ \text { Plasma density (cm }-3) & -- & 5 \times 10^{13} \mathrm{~cm}^{-3} & 1.5 \times 10^{13} \mathrm{~cm}^{-3} \\ \text { Field at mirror (T) } & -- & & \\ \text { Field at midplane (T) } & -- & 60(\text { ions) } & 180 \text { (electrons) } \\ \text { Particle energy (keV) } & -- & 0.16 & 0.45 \\ \text { Injection power (MW) } & -- & (80 \mathrm{kV} \text { beams) } & (60 \mathrm{GHz} \text { ECRH) } \\ \text { (per anchor, trapped) } & & & \end{array}$


TABLE 3. TANDEM MIRROR DEVELOPMENT

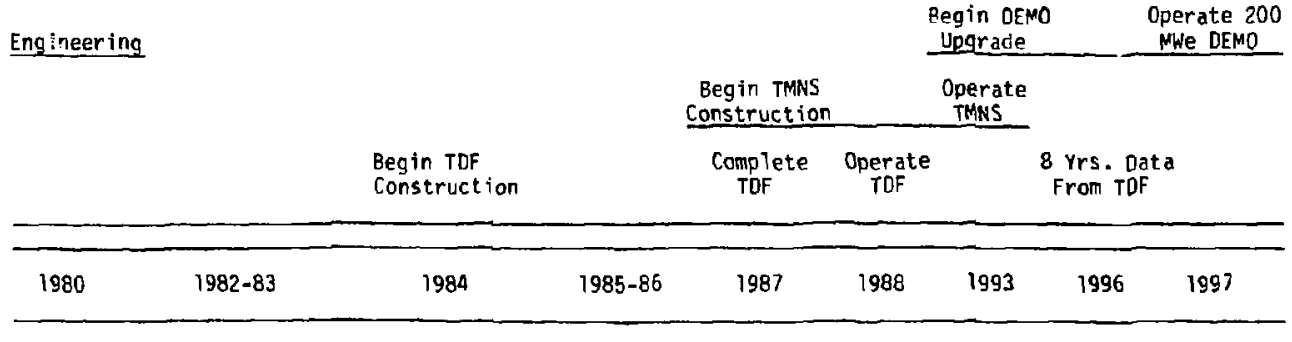

\section{Physics}

TMK data-. adequate

for TDF

base case

TMX-U thermal barrier data-- TARA-: adequate

for TDF

upgrade
MFTF - B

$>1 \mathrm{sec}$

axisymetric

data for

TMNS magnet

design,

confirm TaF

magnet design

\section{adequate}

for TMNS
MFTF-B

Uparade 


\section{TECHNOLOGY DEMONSTRATION FACILITY}

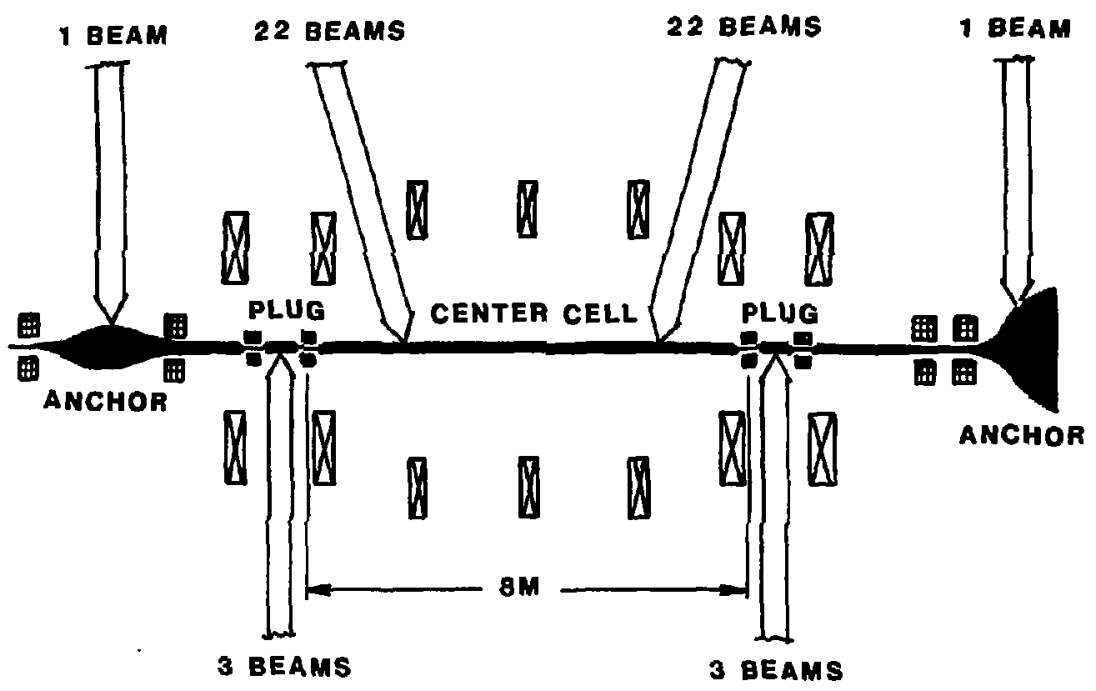

- all BeAMS ARE BoKV

- Miti SUPERCONDUCTING MAGNET

- 两 Cu magnet 
TMX UPGAADE

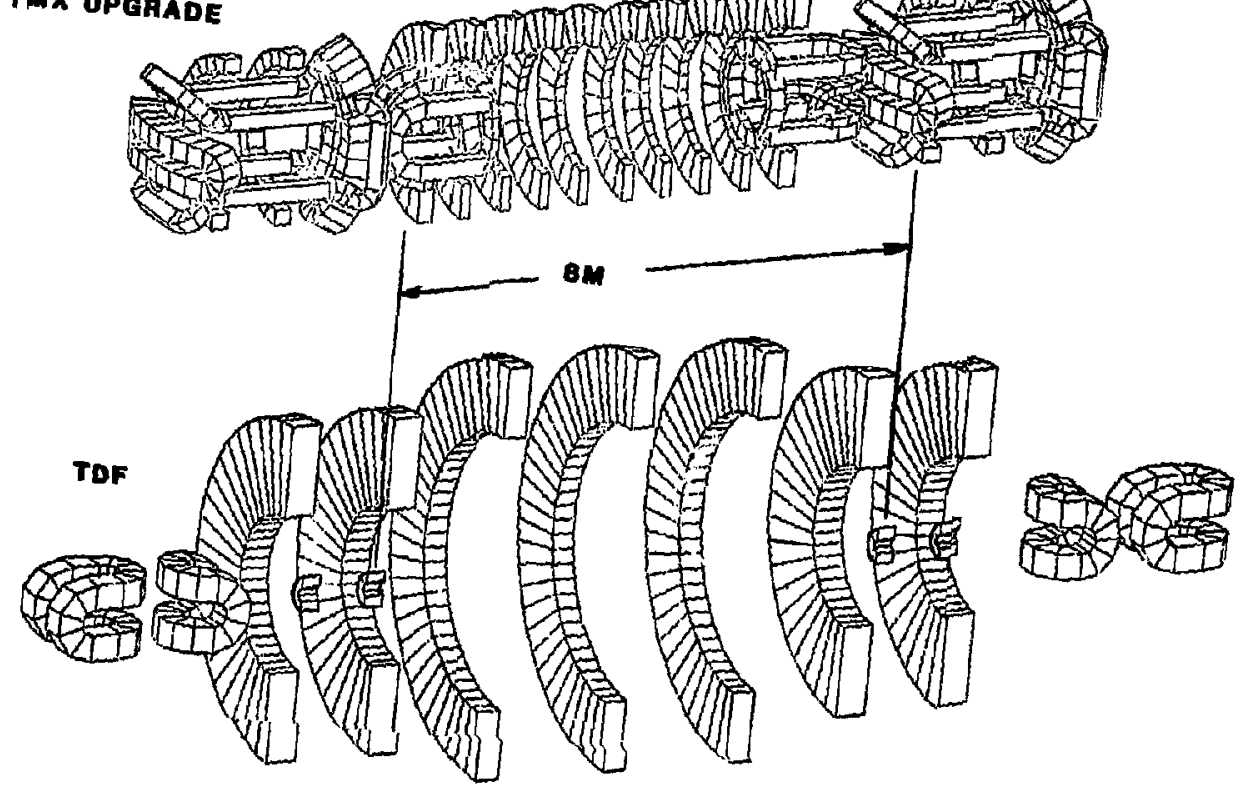

Fowler - Fin. 2 